\title{
The dream of Sisyphus: Mathematics education in South Africa
}

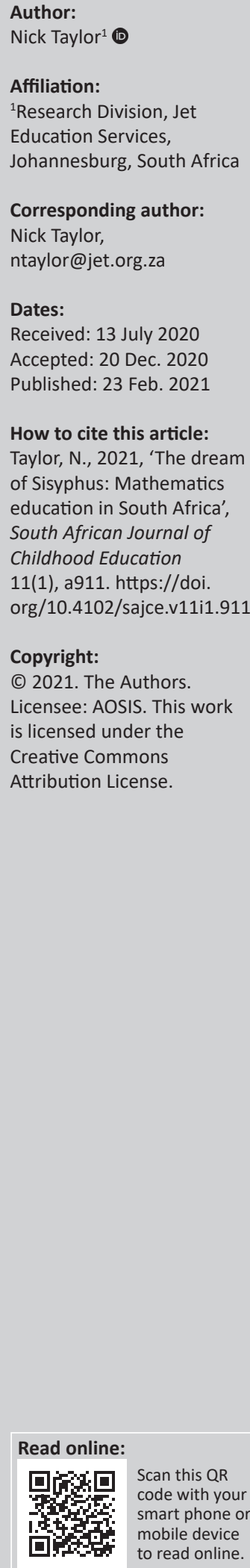

Background: South African schooling is caught in a vicious cycle, characterised by weak initial teacher education (ITE) and weaker-than-average learning outcomes, resulting in low teacher status and attempts to reform schooling by means of continuous professional development (CPD).

Aim: The paper attempts to understand the reasons for poor performance in mathematics and to explore avenues for improvement.

Setting: Teaching in South African schools.

Method: Three mechanisms for improving teaching and learning are identified: ITE, CPD and the management of and support to teachers. Drawing on the research literature, the paper examines the potential of each for reforming the system.

Results: Tests based on the school curriculum indicate that final-year BEd students are quite unprepared to teach mathematics in primary schools, revealing very significant shortcomings in ITE curricula. CPD, where it is well designed and rigorously evaluated, has been shown to have small effects on both teacher knowledge and learner performance. However, unless ITE is reformed at the same time, CPD becomes a never ending task of making marginal differences to the shortcomings of each successive cohort of qualified but incompetent teachers emerging from the universities.

Conclusion: While the weak state of governance in the civil service remains a major obstacle to improved schooling, and while every effort must be made to raise the capacity of inservice teachers, maximal leverage in boosting teacher capacity sits firmly with the universities. While CPD has, at most a few hours a month to bridge huge gaps in teacher knowledge, ITE has at its disposal four years of full-time study with young, plastic minds.

Keywords: mathematics education; high performing school systems; initial teacher education; continuous professional development.

Sisyphus, in Greek mythology, was punished in Hades by having repeatedly to roll a huge stone up a hill only to have it roll down again as soon as he had brought it to the summit. (Encyclopaedia Britannica 2020)

A Sisyphean task is a pointless, fruitless and unrewarding task that must be repeated over and over again; an endless task. (Idioms Online 2020)

\section{Primary school mathematics: A conceptual framework}

At the highest levels, the discipline of mathematics consists of a proliferation of sub-disciplines and topics, many of which have little direct conceptual relation to one another apart from residing within the epistemological frame of the discipline. However, at the level of the primary school, the evolution of the number concept consists essentially of the closely linked set of sub-concepts and procedures depicted in Figure 1.

The ultimate goal of primary school mathematics, as specified in successive South African curricula over the past few decades, is to nurture amongst learners a flexible understanding of proportional reasoning and the faculty to work with rational numbers. This is the central idea required to explore fully all the principal topics in the high school curriculum: the algebraic and graphical representation of polynomial functions, differential and integral calculus, trigonometry, probability and the geometry of similarity. High school students may obtain a 'pass' on the National Senior Certificate (NSC) mathematics examination, but this does not necessarily mean they have mastered the concepts listed in the curriculum. For example, students in Grade 12 may be able to calculate the gradient or derivative of a function by 


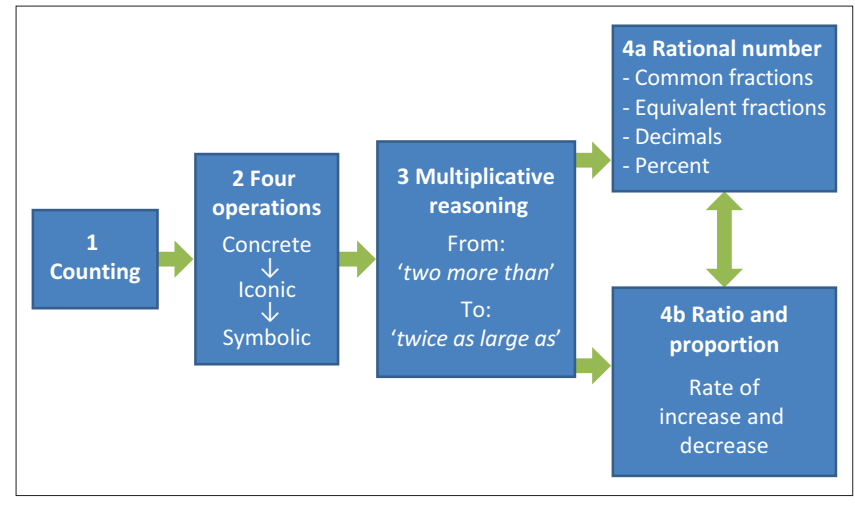

Source: Adapted from Taylor, N., 2019, 'Teacher knowledge in South Africa', in N. Spaul \& J. Jansen (eds.), South African schooling: The enigma of inequality, pp. 263-282, Springer, Cham, Switzerland.

FIGURE 1: The trajectory of the number concept.

plugging numbers into simple formulae, hence satisfying examiners that they are worthy of an NSC certificate. But if they do not possess a good understanding of the rate of change concept, they are likely to fail badly at the tertiary level. Seen from this perspective, it is safe to say that the roots of the country's paucity of graduates in the mathematical and physical sciences lie deep in the primary school.

Laying out the trajectory traced in Figure 1 is not to imply that all learners necessarily must pass through each of the five main conceptual terrains illustrated here. In many cases, the pathways traversed by individuals may loop through these fields in idiosyncratic and iterative ways, and there is no doubt that a few particularly gifted students will leap across fields as they grasp several concepts at a glance. It is also possible to argue for different arrangements of the ideas shown in the figure. These debates aside, the main point captured in the pathway illustrated in Figure 1 is that it is not remotely plausible that a student may exhibit conceptual and procedural fluency with proportional reasoning without grasping the concept of equivalent fractions, which in turn is dependent on a sound understanding of the ideas and procedures associated with multiplicative reasoning.

\section{What are the bottlenecks in South African primary school mathematics?}

It has become a truism that the large majority of South African learners perform poorly at mathematics. Whilst there are signs that performance is improving incrementally at both primary and secondary levels (Reddy et al. 2015; Spaull 2019; Van der Berg \& Gustafsson 2019), even the most optimistic commentators agree that the school system has a long hill to climb before we can be satisfied that it is delivering quality for all learners. Thus, Van der Berg, Gustafsson and Malindi (2020) note that the quality of South African schooling is at a level more typically associated with a low-income country than a middle-income country. In the same vein, Taylor and Robinson (2019) point out that whilst South Africa spends more than 30 times on each primary school child than Uganda, the countries' Southern and Eastern African Consortium for Monitoring Education Quality (SACMEQ) scores have tracked each other closely over nearly two decades.

In order to improve performance, we must first identify exactly where the problems lie. The framework outlined in Figure 1 allows a diagnostic assessment of bottlenecks inhibiting the teaching and learning of mathematics in South African schools.

\section{Bottleneck 1: Arithmetic operations}

In a seminal piece of research conducted nearly two decades ago, Schollar $(2004,2015)$ demonstrated that large numbers of learners, all the way up to and including Grade 7, have not exited the second box of Figure 1, indicating that they have a poor grasp of the four arithmetic operations. Through an analysis of the methods used by learners to perform the operations, Schollar showed that a large proportion of learners used what he referred to as 'unit counting procedures' to perform addition and subtraction problems. Whilst this problem is very widespread in South Africa, it occurs in other countries too, where it has been described as 'calculating-by-counting' (Van den Heuvel-Panhuizen 2008).

What is happening here is that learners are making marks on the page in place of tangible counting aids - such as bottle tops or Diennes blocks - and then to use counting procedures to perform simple arithmetic calculations. Whilst they may have moved from the concrete manifestation of numbers to what Bruner called iconic images (Bruner 1966), they have clearly not made the crucial conceptual leap to using the written numerals as symbols for numbers. They have not completed the transition from tangible to symbolic thinking. Manipulative materials and iconic images are important in facilitating learning in the early grades, but it is clear that many learners, perhaps the majority, are getting stuck in literal thinking patterns and teachers need to find a way of assisting their charges to negotiate the critically important passage to symbolic reasoning. The great power of mathematics lies in abstracting lower level concepts by means of symbolic entities in order to make higher order concepts more manageable and to work more efficiently with larger entities (Taylor \& Reddi 2013). As Gray (2008) comments:

It (the formation of numerical concepts) involves a shift in attention from the objects of the real world to objects of the arithmetical world - numbers and their symbols ( $p$ 82) ... Numerical symbols do not represent either a process or an object: they represent both at the same time. (p. 88)

Schollar's study shows that the key step from concrete and iconic thinking to the use of symbolic entities is not achieved in many South African primary classrooms. These children are not learning to do mathematics, but to use only extremely clumsy counting procedures to perform arithmetic operations. 


\section{Bottleneck 2: Multiplicative reasoning}

Both the handicaps described above - conceptual inflexibility and procedural clumsiness - are abundantly illustrated by Schollar's demonstration of how learners address multiplication and division calculations. This occurs in the third field illustrated in Figure 1: Multiplicative reasoning. Here the learners observed by Schollar conceptualise multiplication and division calculations as repeated addition or subtraction problems. Thus, in order to execute a calculation such as $420 / 20$, the learner will subtract 20 from 420 , and then subtract 20 from the difference, and so on until the dividend is reduced to zero (or a remainder smaller than 20 ), and then count the number of times the subtraction was done, to get the quotient (Schollar 2004, 2015). Needless to say, the labour involved in this process inevitably not only leads to an error along the way but takes so much time that by the end of the procedure, the point of the exercise will probably have been lost.

\section{Bottleneck 3: Teacher knowledge and skills}

How is it that, across the length and breadth of the country, through all the grades, primary school learners use the methods so well captured by Schollar? Is it that teachers do not understand these concepts and their associated procedures themselves, is it that they have a good grasp of the subject knowledge but practice inappropriate pedagogies with their learners or is it a combination?

A number of studies indicate that inadequate subject knowledge on the part of teachers is at least a large part of the problem. Venkat and Spaull (2015), for example conclude from a study of the SACMEQ teacher test scores of South African teachers of mathematics at Grade 6 level that 79\% of teachers have content knowledge levels below that specified by the Grade 6 school curriculum. In other words, they do not understand the curriculum that they are responsible for teaching. Using the same data, Taylor and Taylor (2013) demonstrated that a large proportion of these teachers have themselves failed to progress beyond the second (arithmetic operations) and third (multiplicative reasoning) blocks of Figure 1. They are stuck in the earliest stages of the conceptual trajectory delineated by the school curriculum.

Two mechanisms are available for addressing the knowledge gaps so clearly exhibited in the test scores analysed by these authors: initial teacher education (ITE) and continuous professional development (CPD).

\section{Initial teacher education}

Many of the teachers currently in the system will have been educated through the college system which consisted of over 100 Teacher Training Colleges spread out for convenient access throughout the country. In the early 2000s, under the minister for education Kader Asmal, teaching became an allgraduate occupation and the ITE terrain was reconfigured with the majority of colleges being closed and a small number incorporated into nearby universities. Whilst controversy over the latter move remains alive today (Chisholm 2019), it can be argued that, through the universities, teachers are now being better educated and the poor test scores shown in the preceding paragraphs are likely to improve. To a very limited extent, this thesis holds up: Armstrong (2015) disaggregated the SACMEQ teacher scores by age and found that, in 2007, teachers aged 29 and under - who would all have been beneficiaries of the reconfigured system - scored significantly better than all their older peers in both literacy and maths.

But does 'significantly better' mean that teachers currently produced by the universities are adequately prepared to teach the school curriculum? And what would it mean for Bachelor of Education graduates qualified to teach in the primary school to be 'adequately prepared'? For Alex and Roberts, if teachers are to teach primary mathematics well, then they must have a thorough knowledge of the items listed in Box 1.

It may be argued that these goals for ITE curricula are unambitious and that primary school teachers should know a good deal more maths than this. That may be good and well, but tests conducted by Roberts and her colleagues indicate that BEd students intending to become primary school teachers are not getting anywhere near learning even the first item in Box 1 (how to do the mathematics themselves) and therefore have no chance of mastering the more sophisticated aspects of the maths knowledge for teaching (MKfT) (Ball, Thames \& Phleps 2008) required to be effective teachers of the subject. These tests drew on mathematics chosen from the Curriculum and Assessment Policy Statement (CAPS) document for the mathematics curriculum of foundation and intermediate phases of schooling in South Africa.

The content areas included were whole numbers and operations; rational numbers and operations; geometry; patterns, functions and algebra, and measurement. Test items were mainly from two cognitive categories: lower and higher cognitive demands (Fonseca, Maseko \& Roberts 2018). Whilst 'lower cognitive demand' items were considered to

BOX 1: What primary school teachers need to know to teach mathematics. (1) The mathematical topics at the primary school level that includes a robust
understanding of why particular concepts and procedures within each topic make sense mathematically; $\dagger$

(2) the future use and further development of this content in previous and subsequent grade levels;

(3) appropriate representations, suitable classroom contexts, alternate approaches and methods (such as might be used by children in solving approaches and methods (such as might be used by children in solving
problems);

(4) interconnections and interdependence amongst the content and topics, as well as how a new concept can be built upon other existing ideas and

(5) when the mathematical ideas are developmentally appropriate for children to learn.

Source: Alex, J. \& Roberts, N., 2019, 'The need for relevant initial teacher education for primary mathematics: Evidence from the Primary Teacher Education project in South Africa', in N. Govender, R. Mudaly, T. Mthetwa \& A. Singh-Pillay (eds.), Book of Proceedings, 27th Annual Conference of the Southern African Association for Research in Mathematics, Science and Technology Education (SAARMSTE), University of KwaZulu-Natal, Durban, January 15-17, pp. 59-72.

$\dagger$, This refers to the topics described in the Curriculum and Assessment Policy Statements (CAPS). 
be routine procedures, the 'higher cognitive demand' items involved moves between representations, required insight, connected across topic areas, and/or had no obvious procedure or starting point (Venkat, Bowie \& Alex 2017). Examples of items in the topic area rational numbers are given in Figure 2.

After piloting and refining the test at three universities in 2017, it was administered in the first semester of 2018 to a sample of 1117 first-year BEd students at seven universities. Although this was a convenience sample, defined by maths education lecturers willing to have their student participate, it contains a good cross-section of institutional types: four traditional universities, two universities of technology and one comprehensive university, located across four provinces (Gauteng, Free State, Eastern Cape and Western Cape) and including three historically disadvantaged institutions and four better resourced urban faculties.

The mean score on the test was $48.5 \%$, with a standard deviation of 16.20. Mean scores across five main topic domains were: whole numbers 53.5\%; geometry $60.4 \%$; rational numbers $41.1 \%$; patterns and algebra $44.2 \%$ and measurement 56.2\%. Alex and Roberts (2019:62) commented that these scores have implications for the design of BEd programmes for prospective primary school teachers: sufficient time is required for teachers to be able to develop a deep understanding of the mathematics content, together with the processes and perspectives described in Box 1.

Results from administering the same test to a sample of 282 fourth-year students at three of the same universities indicate very clearly that students had not learnt nearly enough mathematics in nearly four years of BEd study and were obviously nowhere near ready to teach the CAPS curriculum (Table 1).

\section{Lower-cognitive-demand items \\ (A) Is $3 / 7$ smaller than $1 / 2$ ? \\ (B) Calculate $45304 \times 1000$}

Higher-cognitive-demand items

(A) $57 / 150$ is closest to $0.004 ; 0.04 ; 0.4 ; 4$

(B) Which is true: $5 \div 13 / 17$ is smaller than $5 ; 5 \div 13 / 17$ is equal to $5 ; 5 \div 13 / 17$ is greater than 5 ?

Source: Bowie, L., Venkat, H. \& Askew, M., 2019, 'Pre-service primary teachers' mathematical content knowledge: An exploratory study', African Journal of Research in Mathematics, Science and Technology Education 23(3), 286-297. https://doi.org/ 10.1080/18117295.2019.1682777

FIGURE 2: Items in the topic area rational numbers.
The most striking features of these results are the very poor scores exhibited by fourth-year students together with the very minor differences between the first- and fourth-year students shown in this 'quasi-longitudinal' sample. Not only did fourth-year students know very little maths but they also appear to have learnt very little during the 4 years they spend studying. The first- and fourth-year results are not strictly comparable because they belong to different cohorts of students, but it would be surprising if the maths knowledge of fourth-year students at the start of their studies had been significantly different from that of the first-year cohort shown in Table 1.

These students were about to receive a BEd qualification but the majority were patently incompetent to teach maths to primary school learners. Imagine a teacher who battles with the kinds of questions shown in Figure 2 trying to induct learners into the mysteries of equivalent fractions, decimals, percentage, ratio and proportion? Whilst it is not possible to generalise the findings from three institutions to the sector as a whole, a similar test administered to fourth-year students and newly qualified teachers from five other institutions indicated that the results shown in Box 1 reveal a widespread phenomenon (Deacon 2016a). For example, a sample of 158 final-year students at a rural campus scored an average of $26 \%$, with the 46 students who were specialising in maths averaging 37\% (Bowie 2015). These very poor results are not surprising: Bowie (2014; see also Taylor 2014a) has shown that across these five universities, which include examples of all institutional types, the curricula of those student teachers who opted not to specialise in mathematics allocate as little as $5 \%$ of the 4 -year curriculum to the study of the subject. But it is also clear from the test scores that those students who do specialise in maths learn little more than their non-maths counterparts.

These poorly educated but about-to-be qualified teachers are the agents who, unwittingly and through no fault of their own, reproduce the country's poor educational outcomes year after year. Exactly why the subject knowledge of finalyear students is so poor is not entirely clear. Is it merely that insufficient time is allocated to mathematics in BEd curricula; is it that the curricula are inappropriate; or are lecturers themselves employing ineffective pedagogical techniques with their students? These are questions that require further research. But what is clear is that lecturers are awarding qualifications to candidates who are not qualified to teach mathematics in South African primary schools.

TABLE 1: First- and fourth-year scores at three universities, per cent correct.

\begin{tabular}{|c|c|c|c|c|c|c|c|}
\hline Institution & Level (year) & Overall & Whole numbers, operations & Rational numbers & Patterns, functions algebra & Geometry & Measurement \\
\hline \multirow[t]{2}{*}{ A } & First & 58 & 66 & 47 & 63 & 74 & 55 \\
\hline & Fourth & 64 & 68 & 58 & 62 & 79 & 65 \\
\hline \multirow[t]{2}{*}{ B } & First & 51 & 59 & 39 & 56 & 72 & 48 \\
\hline & Fourth & 50 & 56 & 42 & 47 & 69 & 52 \\
\hline \multirow[t]{2}{*}{ C } & First & 41 & 49 & 32 & 42 & 60 & 33 \\
\hline & Fourth & 50 & 52 & 46 & 45 & 63 & 49 \\
\hline
\end{tabular}

Source: Bowie, L., Venkat, H. \& Askew, M., 2019, 'Pre-service primary teachers' mathematical content knowledge: An exploratory study', African Journal of Research in Mathematics, Science and Technology Education 23(3), 286-297. https://doi.org/10.1080/18117295.2019.168277 
However, culpability spreads far wider than the faculties of education - into the upper reaches of university administrations, the relevant government departments and responsible regulatory bodies - and if the country is to improve its performance in maths, then the whole ensemble requires a drastic overall. Curricula governing BEd degrees are subject to two quality assurance checks, one by the Department of Higher Education and the other by the statutory body responsible to Parliament, the Council on Higher Education (CHE). A decade ago, the latter published a wide-ranging review of Master of Education (MEd), BEd, Postgraduate Certificate of Education (PGCE) and Advanced Certificate in Education (ACE ITE) programmes (CHE 2010). Of the 81 entries reviewed, only 39 (48\%) received full accreditation, with 18 (22\%) either not accredited at all or 'On Notice of Withdrawal', and the remainder being conditionally accredited. Across all four types of programmes reviewed, the greatest difficulties lay in programme design, raising for the reviewers the critical question (CHE 2010):

... the extent to which academics responsible for these programmes understand the nature and purpose of each of them and how they are to respond to South Africa's specific needs in the area of teacher education. (p. 147)

The review noted that a fundamental difficulty across all programmes lies in the unsolved tension between the knowledge and practice components: there was overwhelming evidence, for example, that the majority of ACE programmes fulfilled the upgrading intentions of the qualification without adequately addressing the levels of competence students brought with them, and the review concluded that many programmes could not provide appropriate levels of training for the practice that was required by their students. It would not be possible to tell from the evidence available to what extent the quality of ITE has improved in the last decade, but what is clear from the kinds of test scores shown in Table 1 is that the situation is far from satisfactory.

\section{Continuous professional development}

Faced with the failure on the part of ITE providers and regulators to adequately prepare their students for working in schools on the one hand, and manifestly poor teaching in schools on the other, government, non-governmental organisations (NGOs), and local and international donors have for at least three decades collectively invested billions of rand per annum in CPD programmes. A survey conducted in 1995 revealed that 99 NGOs were dedicated to this task with few evaluations between them and only one project using outcome measures to assess the impact (Taylor 1995). Nearly a decade later, Mouton et al. (2013) identified 44 research studies working in the school development sector in which 'credible' evidence of learning effects could be extracted from only 15. In 2014, the DBE budgeted over 1 bn rand for CPD, whilst the private sector contributed at least an equal amount (NEEDU 2017). Much work in the general terrain of CPD goes unevaluated, and where they have been assessed, the results have generally not been encouraging as they are found to have little or no effect (Besharati \& Tsotsotso 2015). International experience mirrors these conclusions: intervention programmes in schools, of which CPD for teachers is a major component, have a poor record in effecting changes in the quality of teaching and learning (LortieForgues \& Inglis 2019).

On a more optimistic note, a number of projects are adopting a research-driven approach which is beginning to exhibit positive effects. One of the most advanced of these is the Wits Maths Connect - Primary (WMC-P) project, an initiative led by Professor Hamsa Venkat, who holds one of the 10 Chairs in Mathematics Education sponsored through a partnership of the First Rand Foundation, the Department of Science and Technology, the National Research Foundation and Anglo American South Africa (CASME 2019).

Commencing in 2011, WMC-P took as its starting point the ubiquitous 'unit counting' strategies employed by primary school learners for performing calculations and described under Bottleneck 1 above. This is surely the most fundamental obstacle to mathematics learning in South African schools and WMC-P has set out to address it through a design research approach (Askew et al. 2019; Venkat 2019; Venkat and Askew 2018). Drawing from the theoretical literature, the team used the Stages of Early Arithmetical Learning (SEAL) (Wright, Martland \& Stafford 2006) as a framework for tracking the development of children's strategies for performing the elementary operations as they progress from simple counting strategies towards more efficient techniques utilising the structure of the number system (Venkat 2019).

Following the lesson observations of Grade 2 teachers in six underperforming schools in Gauteng, 'lesson starter' activities, with supporting materials and a professional development programme, were designed for scaffolding teachers' pedagogy as they assisted their learners to navigate through the SEAL stages (Venkat 2020). Professional development consisted of a combination of discussion workshops followed by observation and coaching in the classroom. Two cohorts of learners were followed, the first from Grades 2 to 3 and the second from Grades 1 to 3.

The effects of these efforts were tracked by means of an action-research programme which used Wright et al.'s (2006) interview-based Learning Framework in Number (LFIN) assessment instrument which is designed to track learner progression through the six-level SEAL hierarchy. Six children in each school were assessed each year, and they showed a clear progression over the years, from the use of crude counting strategies for performing calculations (used by $75 \%$ of Grade 2 learners at baseline), towards a greater facility with working with number relationships and properties.

Early success in moving learners from the earliest stages of the SEAL framework ('counting all') to phase 3 (solving addition tasks using 'count on', 'count-up-to' and 'countdown-from') encouraged the project to move to a 'straight 
for structure' focus. This involved a focus on number relationships and number structure in the lesson starter activities. The adapted design contributed to a further shift up the SEAL hierarchy from Stage 3 (using 'count-down-to' strategies to solve missing subtrahend tasks) to Stage 4 (choosing the more efficient 'count-down-from' and 'countdown-to' for calculation tasks). In 2014, only 5.6\% of the student sample showed evidence of the faculty of with working with number relationships and properties; in 2018, this proportion had increased to $25 \%$ of the cohort.

The project has demonstrated the internal validity of its model of CPD. In other words, the model works under ideal conditions: using a small sample, driven by university lecturers and post-graduate students and enjoying adequate funding. Commendable as the achievements to date have been, the biggest hurdle for projects of this kind lies in establishing their external validity, that is, they can be effective under 'natural' conditions such as those which normally pertain in districts and schools. Through its work with subject advisors, WMC-P is now embarking on this step. This move would entail not only a change in the focus and scale of WMC-P's operations, but would also require an additional evaluative element. Whilst it would be essential for the project to retain the action research component of its work which is important in understanding implementation blockages and the mechanisms driving positive changes - an independent outcome evaluation is required to establish external validity.

It is important for projects such as WMC-P to continue exploring ways of improving the currently very poor teaching of maths in all the country's primary schools, but particularly in schools serving children from poor homes, and the project has an impressive record in this regard to date. At the same time, WMC-P illustrates the limits of CPD, even under experimental conditions. For example, through the number work with teachers described above, the project succeeded in moving $25 \%$ of the learner cohort in six schools, up from $5 \%$ at baseline, out of 'unit counting' strategies to the point where they were working with the structure of the number system. These children are now firmly in the second block of Figure 1, which is where they should be according to the curriculum. This is a great achievement. However, three-quarters of the cohort are still seeing numbers as collections of concrete or iconic objects (e.g. counting on their fingers to calculate $4+5$ ) and are unable to work flexibly with numbers as symbolic entities. Furthermore, this achievement is likely to suffer dilution effects when it goes to scale. Clearly, CPD programmes can have only a limited effect in making up for the very poor ITE experienced by these teachers.

There is a second and perhaps even more obvious reason why CPD cannot compensate for poor ITE: even if CPD could assist all of the country's foundation phase (FP) teachers to get the whole learner cohort to where the curriculum specifies they should be, the process would have to be repeated, year after year, with each badly educated crop of around 20000 newly qualified teachers. This is the
Sisyphean nightmare in which the South African system seems to be stuck: policy makers, donors and teacher educators pay little heed to the very indifferent nature of ITE. At the same time, these actors pour resources into CPD in the hope of closing the gap between where teachers should be (for primary school teachers this is the last two blocks of Figure 1) and where they actually are on graduating (spread somewhere the second and fourth blocks). Not only is this gap far too large to make up during after-school workshops, but the idea of repeating the exercise every year seems the height of folly. Surely, a more permanent solution would be to improve the initial education of teachers in the first place.

It is in recognition of these limitations that members of the WMC-P team have been participating in various initiatives in the ITE terrain, quoting Lee Shulman (1999) as motivation:

The only place to break the vicious cycle that limits the mathematical knowledge of US [United States] teachers is in the development of far more effective mathematics courses in US undergraduate programs. Butcurrent undergraduate mathematics programs seem to have no place for teaching fundamental mathematics for profound understanding. (p. xii)

A report by the CHE on curriculum reform in the tertiary sector reached the same conclusion regarding higher education programmes in South Africa. The report estimated that some $55 \%$ of all higher education entrants would never graduate, attributing this lack of preparedness to the poor quality of schooling and concluding that, if higher education does not bring about systemic reforms within its teaching and learning system, the status quo will largely remain, to the detriment of development, equity and individual advancement (CHE 2013).

\section{The professionalisation of teaching}

The situation described by Shulman in the quote above sounds very much like the state of ITE in South Africa. Taylor and Robinson (2016) have described the vicious-cycle school systems - such as in the United States of America, the United Kingdom and South Africa - as follows: variable and generally weak ITE produces a mixed teaching corps with some good teachers but in general, they have a weak knowledge base and ineffective pedagogical repertoires. As a result, schools perform very differently - with differences in performance mirroring class inequities in the society - and overall performance of the system is unsatisfactory. Consequently, teachers are held in low regard and the most academically able graduates from the school system opt for higher-status professions. Thus, academically weaker students enter education schools, where they receive variable and generally poor teacher education, and the cycle repeats itself.

In an attempt to improve the quality of schooling, policy makers in the vicious-cycle countries respond to this situation in different ways. One approach, in exasperation with the poor quality of professional education offered by universities, 
is to by-pass them. This is what Michael Gove attempted to do in the United Kingdom, on being appointed Secretary of State for Education in May 2010. Declaring that '... teaching is a craft which is best learnt as an apprentice observing a master craftsman or woman', Gove opened new avenues to qualifying as a teacher (Gove 2010). Thus, following a first degree in the relevant teaching subject(s), aspirant teachers would not be required to obtain a professional university qualification but could proceed straight to school for an induction period. As a result, just 5 years later, around half of all new teachers were following one or more of the 'straight for school' routes, although this practice remained controversial (Roberts \& Foster 2016).

A second type of response to a vicious cycle school system is to apply tighter regulatory measures, where governments take it upon themselves to hold teachers accountable at times through punishing, or threatening to punish, teachers whose students do not perform well. However, these performance management measures cannot solve the problem of disappointing school performance, as the failure of the 'No Child Left Behind' programme in the United States demonstrates. As Richard Elmore (2004) asks:

Is it ethical to hold individuals - in this case, educators accountable for doing things they don't know how to do and can't be expected to do without considerable increase in their own knowledge and skill? (p. 280)

Accountability is important and there is too little of it in the South African school system, but it seems perverse to hold teachers accountable for, say, teaching mathematics ineffectively when their own education has been so poor.

A third response to the vicious-cycle syndrome is to imagine that CPD can make up for poor ITE, as seems to be the case in South Africa. Whilst we have argued strongly against this position in the previous section, this is not to dismiss the value of $\mathrm{CPD}$. There is an emerging agreement in the research literature that ITE and CPD should be integrated into a continuum which supports teachers' capacity throughout their careers. However, the two serve different purposes and are not interchangeable: ITE provides teachers with a solid base of the disciplinary and pedagogical knowledge and skills that they will need for their task, whilst CPD allows them to update their knowledge and skills, to learn from their peers and to adapt to changes in the curriculum (Musset 2010). Continuous professional development must start where ITE leaves off, and as the SACMEQ results show, many South African teachers are very weak. Under these circumstances, CPD must start from a low base.

Vicious-cycle systems exhibit a laissez fare attitude towards ITE and, where they do attempt to reform the school system, do so by means of one or other combination of accountability and teacher support measures. In contrast, starting with the seemingly self-evident aphorism 'The quality of an education system cannot exceed the quality of its teachers' (Barber \& Mourshead 2007:19), these authors gave strong impetus to the research literature tracking a quite different approach to school reform. They note that this axiom is clearly not selfevident to many analysts and policymakers, with the debate about how to improve the world's school systems all too often (Barber \& Mourshead 2007):

... guided by a set of beliefs that have little basis in fact: namely that it is possible to make substantial, long-term improvements to the school system without fundamentally raising the quality of the people who enter the teaching profession. (p. 26)

Continuing this tradition, Darling-Hammond et al. (2017), Schleicher (2018), Tucker (2019) and many others describe how 'high-performance school systems' - adopt a wholesystem approach to school improvement, in which three elements are tightly integrated. Firstly, they rigorously select the most highly motivated and academically able students into ITE programmes. Secondly, the preparation of teachers is intensive, focusing on disciplinary knowledge, pedagogical content knowledge and plenty of craft experience. Thirdly, the career paths of teachers are managed by an expertfocused civil service directed towards identifying, developing and promoting the best instructional leadership potential.

\section{Teaching as a profession}

The foundations of the three-pronged strategy adopted by high-performance school jurisdictions is a 'teaching as profession' approach, in which practice is guided by a growing knowledge base developed in the universities, schools and classrooms by means of a combination of theoretical and empirical research (Darling-Hammond \& Hyler 2013; Taylor 2014b). This approach draws upon two features common to professions: they share a common body of knowledge and skills which they use to guide their practice and the standards governing this body of knowledge are developed and policed by a professional body peopled by expert members of the profession (Abbott 1988). In highperforming school systems, these principles guide the ensemble of practices related to the selection, preparation and deployment of teachers. The first two characteristics of such systems, on which the third is heavily dependent, are the responsibility of the ITE sub-system. However, reforming weak ITE systems is not easy, as Tucker (2020) notes concerning schooling in the US:

Our schools of education are the weakest link in our public education system, and, of all the system's parts, they may be the hardest to change with the tools available to policy makers. Perhaps that's why we don't really even try. (p. 1)

\section{Selection into initial teacher education}

The starting point for optimising the education of teachers is the motivation and academic proficiency of student teachers. According to Barber and Mourshead (2007:23), attracting high-quality candidates into teaching does not depend in the first instance on salary: surveys show that most people entering the profession do so for a number of reasons, foremost of which is to help a new generation succeed in a world in which skills and knowledge are crucial to success. 
However, without competitive conditions of service, the top graduates from the school system are likely to be attracted to one of the many other options open to them. Thus, whilst teacher salaries in the majority of high-performing countries may not be exceptionally high, they provide a comfortable living wage, and are competitive with similarly qualified careers. Furthermore, some countries provide fully funded opportunities to advance within the teaching profession, as well as bonuses for teachers who perform well (Tan, Low \& Sim 2017).

In this regard, South Africa reflects the situation typical of the vicious-cycle systems: the weakest students enter education faculties, not necessarily driven by a desire to make a difference to the lives of children and the public good, but as a last-choice option, driven by the desire to achieve some sort of university qualification (Deacon 2016b). This situation is clearly exhibited in the results of the National Benchmark Tests (NBTs) taken by the majority of all university entrants. In the 2019 NBT intake cycle, over 75000 university applicants wrote both the Academic Literacy (AL) and Quantitative Literacy (QL) tests and over 58000 sat for the Mathematics (MAT) test. The mean performance of candidates intending to study Education was second weakest of applicants to all faculties with only candidates for the Allied Healthcare/ Nursing faculties scoring lower (CETAP 2020). Scores on the NBT are classified according to three levels - Basic, Intermediate and Proficient, with applicants falling into the Basic band defined as (CETAP 2020):

Test performance reveals serious learning challenges: it is predicted that students will not cope with degree-level study without extensive and long-term support, perhaps best provided through bridging programmes (i.e. non-credit preparatory courses, special skills provision) or FET provision. Institutions admitting students performing at this level would need to provide such support themselves. (p. 18)

Of the cohort of applicants to faculties of education in 2019, 29\% were classified as Basic for AL, 74\% for QL and $86 \%$ for MAT. These very discouraging scores underscore a central feature of any vicious-cycle school system, such as the one maintained by South Africa. Teaching is one of the last choices school leavers will make, given the very poor performance of the system and the consequent low status of teaching. Tucker (2019) notes that the very high turnover of teachers in the United States compared with its close neighbour Canada can be attributed to poor motivation on the part of a high proportion of American teachers.

In stark contrast, high performing systems have reached a virtuous cycle, where school performance is not only high but exhibits high levels of equity, teaching is viewed as an attractive, high-status profession and the best students apply for and are selected into ITE. Finland is a good example, where selection of students is a rigorous process involving first a national entrance exam based on selected research articles on teaching and education, followed by a consideration of the candidates' matriculation scores, out-of- school accomplishments, and their motivation and ability to engage with children (Sahlberg 2012).

In Singapore, the selection of teacher education candidates is equally rigorous to the extent that only one of eight shortlisted applicants makes it through the selection interview, which is just the third of four steps, the last step involving the monitoring of students during ITE, and deselecting those who do not exhibit the required dedication and aptitude (Darling-Hammond et al. 2017). As is the case in Finland, rigorous interviews also play a role early in the selection process, with candidates screened for communication skills, a passion for teaching and the potential to become a suitable role model for learners.

In the highly fragmented ITE system in South Africa, there is no such consensus regarding the attributes of a student who has the potential to become an excellent teacher and there appears to be very little attempt to screen students at entry (Deacon 2016b), even though the generous bursaries offered to students and the secure conditions of service for teachers (Gustafsson \& Maponya 2020) would act as strong incentives to the brightest and the best, if only the field were not tarnished by the very poor image of teachers in the public eye.

The Department of Higher Education and Training (DHET) is showing every sign of being alert to this problem. A draft revision of the Minimum Requirements for Teacher Education Qualifications (MRTEQ) issued for public comment in 2018, DHET notes that language competence and mathematics competence are serious developmental challenges for the country, and that these disciplines must be a primary focus of the BEd in both the foundation (Grades 1-3) and intermediate (Grades 4-6) phases (DHET 2018). The proposed policy states that all fountation phase (FP) and intermediate phase (IP) teachers are expected to teach both languages and mathematics. In order to prepare them for BEd studies in these subjects, they must have taken and passed in the NSC with at least $50 \%$. If mathematics literacy was taken instead of mathematics, the expected pass level is 60\% (level 5).

These entrance requirements had not been approved at the time of writing, and are likely to receive stiff opposition from the universities . Resistance is likely to arise because, until the status of teaching is raised and students from the upper quartile of performance in the NSC begin to apply to education faculties, the numbers of students who qualify to enter the BEd will be severely constrained by the proposed change in entrance requirements. The consequent reduction in student numbers, in turn, will negatively affect the income of institutions who offer ITE qualifications. A second factor is likely to increase pressure on government to drop the proposed new entrance requirements: under the twin influences of a bump in population growth and an aging teacher corps, the demand for teachers in the next decade is predicted to nearly double before settling back to current levels (Gustafsson 2020). Under these conditions, the 
temptation for government is to reduce the standards of both entry into and qualification from ITE, a path chosen by many developing countries (Taylor and Robinson 2019). This option should be strenuously resisted because the appointment of inadequately prepared teachers embeds a 40year problem in the system as these poorly educated teachers work their way towards retirement.

Prescient to the problem of a potential drop in the number of students as a result of the application of the new entrance requirements, the draft MRTEQ offers a loophole: prospective students who do not achieve the required level of performance in the NSC and who are passionate about becoming teachers in the FP and/or IP must be directed to the appropriate entry-level programme to develop the entry-level competences (DHET 2018:26, 27). Taking into account the very poor state of mathematical knowledge of first-year BEd students currently (Table 1), it would be well for students who do not meet the proposed new entrance criteria for mathematics to spend a year in an entry-level programme in which they achieve at least the first item listed in Box 1 with respect to the topics summarised in Figure 1. This will provide a solid foundation, opening time in the BEd to focus on more sophisticated aspects of these topics, together with research evidence concerning MKfT, including common errors made by children and strategies for remediating conceptual and procedural missteps. Alternatively, the first year of the BEd could be dedicated to ensuring that students have a good grasp of at least the primary school mathematics curriculum.

\section{The initial teacher education curriculum}

The curriculum is the life-blood of the school system: it captures the knowledge, skills and attitudes valued by the society it serves. It follows that the ITE curriculum should prepare teachers to convey the school curriculum to their learners. The curriculum is not the same as the syllabus, which in South Africa's case is the CAPS. Syllabi tend to focus on academic aspects which are but a part of the curriculum. Equally important is the moral dimension, which is why it is important to select teachers who are undiscriminating in their love of children and are energised by working with them. These are the attitudes that a caring society values, wishes to convey to each emerging generation and which prospective teachers should consolidate and refine during their years of professional preparation.

Nor should a strong work ethic take second place in nurturing the professional teacher: teachers' comportment tends to rub off on their students. In this regard, judging from the very little mathematics learnt by South African student teachers reflected in Table 1, it is clear that the programmes are very undemanding and likely to foster an attitude that schooling is a lackadaisical enterprise. The strong professions, in stark contrast, place their students on rigorous programmes which are demanding in terms of intellectual challenge, procedural dexterity and perseverance. It is through immersion in the subject discipline that the professional consciousness of the teacher is specialised (Bernstein 1996). And it is through working hard, under conditions of academic challenge and high expectations, that a strong work ethic is built.

Turning to the intellectual aspects of the ITE mathematics curriculum, we have endorsed the attributes most succinctly described by Alex and Roberts (2019) and captured in Box 1. There does seem to be an emerging consensus towards this view amongst education faculties in South Africa. For example, a survey conducted in five institutions by the Initial Teacher Education Research Project (ITERP) initiative found that the IP curricula for mathematics at four of the faculties focuses mainly on the mathematics content that South African learners will deal with in Grades $4-9$ but, encouragingly, is generally dealt with at a deeper level than expected at school and with a specific focus on the specialised content knowledge required by teachers (Bowie 2015). However, as we have noted, the intensity and depth of this focus leaves much to be desired. At the same time, the fifth institution surveyed one of the largest providers of teachers in the country focuses on a superficial treatment of mathematical content typically taught to university students. Furthermore, the survey revealed a great deal of diversity in the mathematics methodology courses offered across the institutions making it very difficult to draw out emerging themes. In short, whilst there are some signs of convergence amongst ITE mathematics curricula for primary school teachers, there is obviously a long way to go towards developing the body of knowledge essential to putting teaching and teacher education onto a professional track.

A promising development in this direction is a draft set of knowledge and practice standards developed under the auspices of the Primary Teacher Education Project (PrimTEd 2020a). PrimTEd is an initiative of DHET and in this regard government is showing an understanding that in order to professionalise teaching, the standards which shape curriculum development at the institutional level must be formulated by practitioners and not dictated by the government (DHET 2015, 2018). This is the most essential feature of the strong professions. The development of these standards is but the first step in the protracted process required to develop a body of knowledge which guides professional practice, but it is an important one, without which systemic school reform cannot begin.

Whilst current (DHET 2015) and emerging (DHET 2018) state policies prioritise the foundation disciplines of literacy, language and mathematics, there is a great deal else that is useful for teachers to know, including historical and philosophical perspectives on education, understanding the physiology and psychology of child development, and gaining insights into the relationship between schooling, society and the economy, to mention just the most obvious examples. But it is not possible to study any of these in any depth without the intellectual tools provided by the foundation disciplines of literacy and mathematics. 
Regarding the intellectual demand of the ITE curriculum, the Finnish system is at the cutting edge worldwide. Having selected students on the strength of their motivation and strong literacy and numeracy skills, the 5-year Master's programme is able to move confidently into an intensive study of the deeper principles of the school disciplines and associated pedagogical content knowledge, and to adopt the kind of inquiry-oriented approach to issues of curriculum, assessment and pedagogy are so vividly illustrated in the WMC-P project. Sahlberg (2012) describes the Finnish ITE curriculum as follows:

Teacher education is now research-based, meaning that it must be supported by scientific knowledge and be focused on thinking processes and cognitive skills employed in conducting research ... A particular principle ... is systemic integration of scientific educational knowledge, didactics (or pedagogical content knowledge), and practice ... (p. 6)

In terms of curriculum content, prospective primary school teachers in Finland must complete coursework in the disciplines they will teach: Finnish, mathematics, history, science, drama, music and physical education; in addition, they do coursework in pedagogy, communication and language development, research and analysis, and the theory of child development (Darling-Hammond et al. 2017; NCEE 2016). Through a detailed study of ITE curricula in five high-performing jurisdictions - Australia (particularly New South Wales and Victoria), Canada (Alberta and Ontario), Finland, Shanghai and Singapore - Darling Hammond and her colleagues conclude that whilst the details may differ, three themes are common: strong preparation in content and pedagogy, connected to the common curriculum and diverse students to be taught, and well-mentored clinical experiences.

With regard to the last, the quality of school-based mentors is of particular importance and does not end with graduation, but continues into the first year of practice. In Finland, for example, at least two of three clinical placement periods during the course of ITE are at 'teacher training schools' associated with the university's teacher education program (Darling-Hammond et al. 2017): like teaching hospitals linked to university medical faculties, these schools are staffed by expert teachers who can demonstrate researchbased practices and who also continually engage in research and inquiry, connecting theory and practice. All eight universities offering ITE in Finland have at least one teacher training school associated with them, and they also work with other partner or 'field' schools, which are organized to support teacher learning.

South African policy makes provision for both teaching schools to receive students during the practicum, and teaching practice schools linked to university education faculties (DBE/DHET 2011). Only the university of Johannesburg has to date responded to the call for teaching schools, establishing the first teaching school on its Soweto campus in 2010 (Ramsaroop \& Gravett 2017). With respect to teaching practice schools, North-West University has begun to pilot a system for a more rigorous quality assurance system aimed at strengthening the current very weak arrangements regarding both the selection of schools and the mentoring of student teachers (PrimTEd 2020b).

\section{The deployment and management of teachers}

The close links between education faculties and schools illustrated in the Finnish system is part of the integration of the various components of the school system in highperforming countries. Thus, in the best performing school systems, ITE and CPD are complementary, where CPD is an integral part of a teacher's career, used to share best practice and provide the skills required for career progression. In order to achieve an integrated system, education ministries need to articulate a clear strategy with explicit roles for leaders at every level of the system, and maintain the strategy consistently over long periods of time.

One of the most wasteful instances of poor alignment is when the selection of educators into positions of leadership is not based on the requirements of the job on the one hand, and the experience, knowledge and skill of prospective candidates on the other. Delivering the curriculum is a highly technical task, best enhanced by promoting people with the best knowledge and skills into positions of mentorship and other aspects of instructional leadership. Not only does this make the best use of available human resources, but it sharpens the motivation of young teachers, spurring them on to develop their skills in the interests of gaining promotion.

Yet in many countries, including South Africa, these criteria are ignored, with candidates being appointed according to seniority or nepotistic and corrupt procedures (DBE 2016; DPME/DBE 2017). A high-performing school system requires high morale and motivation amongst educators at all levels. When any teacher sees educators less skilled than herself/ himself being promoted, resentment and lack of respect are engendered, creating the worst kind of atmosphere for the teamwork required to deliver the curriculum. And how much can a student teacher learn about pedagogy from a school-based mentor whose own learners can read no more than six or seven common words in a minute? How much guidance can a newly qualified teacher get from a mathematics subject advisor whose main claim to fame is that she is the local shop steward for the union which controls access to promotion posts? In the face of weak accountability, managerial inefficiency and widespread nepotism and corruption, reform of the South African school bureaucracy seems a long way off. The South African government has shown a singular lack of appetite for undertaking the public sector reform mapped out in the National Development plan in 2011 (NPC 2011). What can happen immediately, though, is to start at the most important node in the school system: the ITE sector. 


\section{Conclusion}

The South African school system contains many of the elements which characterise high-performance systems. Examples include a policy framework which provides for the preparation and management of a professional workforce; a university-based, relatively long period of training which is generously funded by the state and good conditions of service. In addition, career paths are structured to provide for instructional leadership at school, district and provincial levels; a performance management system is in place and opportunities for professional development abound.

However, these latter mechanisms cannot achieve more than marginal gains: they are like accelerating a car through wheel-spinning mud, lacking the essential element which provides the traction needed to make them effective: knowledgeable educators. How can a teacher, who can barely deal with multiplication herself, be held accountable for her learners' scores on proportional reasoning? And until the university sector begins to pay more than lip-service to the development of professional teachers, the school system cannot move out of its current state of chronic underperformance.

\section{Acknowledgements Competing interests}

The author declares that he has no financial or personal relationships that may have inappropriately influenced him in writing this research article.

\section{Author's contribution}

N.T. is the sole author of this article.

\section{Ethical consideration}

This article followed all ethical standards for research without direct contact with human or animal subjects.

\section{Funding information}

This work was supported by the Zenex Foundation.

\section{Data availability}

Data sharing is not applicable to this article as no new data were created or analysed in this study.

\section{Disclaimer}

The views and opinions expressed in this article are those of the author and do not necessarily reflect the official policy or position of any affiliated agency of the author.

\section{References}

Abbott, A., 1988, The system of professions: An essay on the division of expert labour, University of Chicago Press, Chicago, IL.
Alex, J. \& Roberts, N., 2019, 'The need for relevant initial teacher education for primary mathematics: Evidence from the Primary Teacher Education project in South Africa', in N. Govender, R. Mudaly, T. Mthetwa \& A. Singh-Pillay (eds.), Book of Proceedings, 27th Annual Conference of the Southern African Association for of Proceedings, 27th Annual Conference of the Southern African Association for
Research in Mathematics, Science and Technology Education (SAARMSTE), Research in Mathematics, Science and Technology Education
University of KwaZulu-Natal, Durban, January 15-17, pp. 59-72.

Armstrong, P., 2015, 'Teachers in the South African education system: An economic perspective' Dissertation presented for the degree Doctor of Philosophy perspective, Dissertation presented for the degree Doctor of Philosophy
(Economics), Faculty of Economic and Management Science, Stellenbosch University.

Askew, M., Venkat, H., Abdulhamid, A., Mathews, C., Morrison, S., Ramdhany, V. et al., 2019, 'Teaching for structure and generality: Assessing changes in teachers mediating primary mathematics', in $M$. Graven, $H$. Venkat, A. Essien \& P. Vare mediating prinary mathematics', in (eds.), Proceedings of the 43rd Conference of the International Group for the
Psychology of Mathematics Education, Vol. 2, PME, Pretoria, pp. 41-48.

Ball, D.L., Thames, M.H. \& Phleps, G., 2008, 'Content knowledge for teaching: What makes it special?', Journal of Teacher Education 59(5), 389-407. https://doi. org/10.1177/0022487108324554

Barber, M. \& Mourshead, M., 2007, How the world's best-performing school systems come out on top, McKinsey \& Company, viewed 25 March 2019, from https:// www.mckinsey.com/industries/social-sector/our-insights/how-the-worlds-bestperforming-school-systems-come-out-on-top.

Bernstein, B., 1996, Pedagogy, symbolic control and identity, Taylor and Francis, London.

Besharati, N.A. \& Tsotsotso, K., 2015, In search for the education panacea: A systematic review and comparative meta-analysis of interventions to improve learner achievement in South Africa, Unpublished manuscript, University of the Witwatersrand, Johannesburg.

Bowie, L., 2014, Initial teacher education project: Report on mathematics courses for intermediate phase student teachers at five universities, JET Education Services, Johannesburg.

Bowie, L., 2015, Initial teacher education project: Report on performance in ITERP Maths test, JET Education Services, Johannesburg.

Bowie, L., Venkat, H. \& Askew, M., 2019, 'Pre-service primary teachers' mathematical content knowledge: An exploratory study', African Journal of Research in Mathematics, Science and Technology Education 23(3), 286-297. https://doi.org/ Mathematics, Science and Technology

Bruner, J., 1966, Toward a theory of instruction, Belkapp Press, Cambridge, MA.

CASME, 2019, The mathematics education chairs initiative: Public communication learning brief, viewed 28 March 2020, from https://www.casme.org.za/ uploads/2/9/4/4/29442955/18329_mathseducation_book_digital.pdf.

CETAP, 2020, The national benchmark tests. National report: 2019 intake cycle, Centre for Educational Testing for Access and Placement, University of Cape Town, viewed 18 May 2020, from https://nbt.uct.ac.za/sites/default/files/NBT\%20 National\%20Report\%202019.pdf.

CHE, 2010, Report on the national review of academic and professional programmes in education, HE Monitor No 11, Council on Higher Education, Pretoria.

CHE, 2013, A proposal for undergraduate curriculum reform in South Africa: The case for a flexible curriculum structure. Report of the Task Team on Undergraduate Curriculum Structure, Council on Higher Education, Pretoria.

Chisholm, L., 2019, Teacher preparation in South Africa: History, policy and future directions, Emerald Group Publishing, Bingley.

Darling-Hammond, L., Burns, D., Campbell, C., Goodwin, A., Hammerness, K., Low, E. et al., 2017, Empowered educators: How high-performing systems shape teaching quality around the world, Jossey-Bass, San Francisco, CA.

Darling-Hammond, L. \& Hyler, M., 2013, 'The role of performance assessment in developing teaching as a profession', viewed 11 November 2015, from http:// www.rethinkingschools.org/archive/27_04/27_04_darling-hammond_hyler. shtml.

DBE, 2016, Report of the ministerial task team appointed by Minister Angie Motshekga to investigate allegations into the selling of posts of educators by members of teachers unions and departmental officials in provincial education departments, Department of Basic Education, Pretoria.

DBE/DHET, 2011, Integrated strategic planning framework for teacher education and development in South Africa, Department of Basic Education and Department of Higher Education and Training, Pretoria.

Deacon, R., 2016a, The initial teacher education research project: Newly qualified intermediate phase teachers in South Africa: Final report on the ITERP NQT Symposium, July 2015, JET Education Services, Johannesburg.

Deacon, R., 2016b, The initial teacher education research project: Final report, JET Education Services, Johannesburg.

DHET, 2015, 'Revised policy on the minimum requirements for teacher education qualifications', Department of Higher Education and Training, Pretoria, Government Gazette No. 38487, 19 February 2015.

DHET, 2018, The minimum requirements for teacher education qualifications (as revised 2018). Draft for comment, Issued 29 October 2018, Department of Higher Education and Training, Pretoria.

DPME/DBE, 2017, Implementation evaluation of the national curriculum statement grade $R$ to 12 focusing on the curriculum and assessment policy statements (CAPS), Department of Planning, Monitoring and Evaluation/Department of Basic Education, Pretoria.

Elmore, R., 2004, 'Conclusion: The problem of stakes', in S. Fuhrman \& R. Elmore (eds.), Redesigning accountability systems for education, pp. 274-296, Teachers College Press, New York, NY.

Encyclopaedia Britannica, 2020, The Editors of Encyclopaedia, 'Sisyphus', viewed 10 July 2020, from https://www.britannica.com/topic/Sisyphus. 
Fonseca, K., Maseko, J. \& Roberts, N., 2018, 'Students mathematical knowledge in a bachelor of education (foundation or intermediate phase) programme', in a bachelor of education (foundation or intermediate phase) programme, in (1) Pro 24 th Anual National of South Africa, AMESA 2018 Long Paper, University of the Free State, Bloemfontein Campus, Free State, June 25-29, pp. 124-139.

Gove, M., 2010, Speech to the National College Annual Conference, Birmingham 16 June 2010, viewed 12 June 2016, from https:/www govuk/government/ speeches/michael-gove-to-the-national-college-annual-conference-birmingham.

Gray, E., 2008, 'Compressing the counting process: Strength from the flexible interpretation of symbols', in I. Thompson (ed.), Teaching and learning early number, 2nd edn., pp. 82-94, Open University Press, Maidenhead.

Gustafsson, M., 2020, Teacher demand in South Africa in 2019 and beyond, Research on Socioeconomic Policy (RESEP), Stellenbosch University, Stellenbosch.

Gustafsson, M. \& Maponya, T., 2020, 'Are South Africa's teachers among the best paid in the world? Using household assets as a proxy for monetary pay', Stellenbosch Economic Working Papers: WP08/2020, Research on Socio-economic Policy, Stellenbosch University.

Idioms Online, 2020, 'Sisyphean Task', viewed 10 May 2020, from https://www. idioms.online/sisyphean-task/\#: : text=Meaning\%20 of\%20ldiom\%20 'Sisyphean\%20Task,1.

Lortie-Forgues, H. \& Inglis, M., 2019, 'Rigorous large-scale educational RCTs are often uninformative: Should we be concerned?', Educational Researcher 48(3) 158-166. https://doi.org/10.3102/0013189X19832850

Mouton, J., Wildschut, L., Richter, T. \& Pocock, R., 2013, Review project final revised report. Review of the school development sector, Evaluation Research Agency (ERA), Stellenbosch.

Musset, P., 2010, 'Initial teacher education and continuing training policies in a comparative perspective: Current practices in OECD countries and a literature review on potential effects', OECD Education Working Papers, No. 48, OECD review on potential effects', OECD Education Working Paper
Publishing, Paris. http://doi.org/10.1787/5kmbphh7s47h-en

NCEE, 2016, Empowered educators how high-performing systems shape teaching quality around the world. Policy brief: Preparing profession ready teachers, The National Center on Education and the Economy, viewed 01 April 2020, from http://ncee.org/wp-content/uploads/2017/02/RecruitmentPolicyBrief.pdf.

NEEDU, 2017, NEEDU national report 2014: Prepared for the twenty-first century? The quality of high school education in South Africa, National Education Evaluation and Development Unit, Pretoria.

NPC, 2011, Our future, make it work: National development plan 2030, National Planning Commission, Pretoria.

PrimTEd, 2020a, Draft PrimTEd Mathematical Knowledge and Practice (MKP) standards for prospective FP and IP teachers, Department of Higher Education and Training: Primary Teacher Education Project, viewed 19 June 2020, from https://www.jet.org $\mathrm{za}$ /clearinghouse/projects/primted/standards/mathematics-teacher-standards/ primted-k-p-standards-for-mathematics-19nov19.pdf/view.

PrimTEd, 2020b, Teaching practice: Guidelines for initial teacher education programmes, Department of Higher Education and Training: Primary Teacher Education Project viewed 19 June 2020, from https://www.jet.org.za/clearinghouse/projects/ primted/curriculum-frameworks/work-integrated-learning-1.

Ramsaroop, S. \& Gravett, S., 2017, 'The potential of teaching schools in enabling student teacher learning for the teaching profession', Journal of Curriculum Studies 49(6), 848-865. https://doi.org/10.1080/00220272.2017.1325516

Reddy, V., Zuze, T., Visser, M., Winnaar, L., Juan, A., Prinsloo, H. et al., 2015, Beyond benchmarks: What 20 years of TIMSS data tell us about South African education, Human Sciences Research Council, Pretoria.

Roberts, N. \& Foster, D., 2016, 'Initial teacher training in England', House of Commons Library: Briefing Paper No 6710, 09 May 2016.

Sahlberg, P., 2012, 'The most wanted: Teachers and teacher education in Finland', in L. Darling-Hammond \& A. Lieberman (eds.), Teacher education around the world: Changing policies and practice, Routledge, London.

Schleicher, A., 2018, World class: How to build a 21st-century school system: Strong performers and successful reformers in education, OECD Publishing, Paris. http:// doi.org/10.1787/4789264300002-en

Schollar, E., 2004, 'The primary mathematics research project: An empirical investigation into the outcomes of mathematics education in South African primary schools', Unpublished Research Report.

Schollar, E., 2015, 'The primary mathematics research project: 2004-2012: An evidence-based programme of research into understanding and improving the outcomes of mathematical education in South African Primary schools', Thesis Submitted for the Degree of Doctor of Philosophy, Department of Sociology, University of Cape Town.
Shulman, L., 1999, 'Introduction', in L. Ma (ed.), Knowing and teaching elementary mathematics: Teachers' understanding of fundamental mathematics in China and the United States, pp. xvii-xxii, Lawrence Erlbaum Publishers, Hillsdale, NJ.

Spaull, N., 2019, 'Equity: A price too high to pay?', in N. Spaull \& J. Jansen (eds.), South African schooling: The enigma of inequality, pp. 1-24, Springer, Cham, Switzerland.

Tan, O., Low, E. \& Sim, J., 2017, 'Underpinning philosophy of teacher education in Singapore: A values-driven paradigm', in O. Tan, W. Liu \& E. Low (eds.), Teacher education in the 21st century: Singapore's evolution and innovation, pp. 45-57, Springer, Singapore.

Taylor, N., 1995, 'INSET, NGOs and evaluation: A review', in P. Vinjevold (ed.), Presentation to the Kenton-at-Settlers Conference, 27-30 October, Quality and validity in INSET evaluation, Proceedings of the JET Conference, February 27 viewed, 06 January 2020, from https://www.jet.org.za/resources/Vinjevold_ Conference_Quality_and_Validity_27_Feb_96.pdf/view.

Taylor, N., 2014a, Initial teacher education research project: An examination of aspects of initial teacher education curricula at five higher education institutions. Summary Report, JET Education Services, Johannesburg.

Taylor, N., 2014b, 'Knowledge and teacher professionalism: The case of mathematic teaching', in M. Young \& J. Muller (eds.), Knowledge, expertise and the professions, pp. 171-184, Routledge, London.

Taylor, N., 2019, 'Teacher knowledge in South Africa', in N. Spaull \& J. Jansen (eds.), South African schooling: The enigma of inequality, pp. 263-282, Springer, Cham, Switzerland.

Taylor, N. \& Taylor, S., 2013, 'Teacher knowledge and professional habitus', in N. Taylor, S. Van der Berg \& T. Mabogoane (eds.), Creating effective schools: Report of South Africa's National School effectiveness study, pp. 204-233, Pearson, Cape Town.

Taylor, N. \& Reddi, B., 2013, 'Writing and learning mathematics', in N. Taylor, S. Van der Berg \& T. Mabogoane (eds.), Creating effective schools: Report of South Africa's National School effectiveness study, pp. 204-233, Pearson, Cape Town.

Taylor, N. \& Robinson, N., 2016, Towards teacher professional knowledge and practice standards in South Africa, JET Education Services, Johannesburg, viewed 07 May 2020, from www.jet.org.za.

Taylor, N. \& Robinson, N., 2019, Secondary education in sub-Saharan Africa: Teacher preparation and support. Case study: South Africa: Teacher preparation and support. Literature review, viewed 07 May 2020, from www.jet.org.za.

Tucker, M., 2019, Leading high-performance school systems: Lessons from the world's best, ASCD and NCEE, Alexandria, VA.

Tucker, M., 2020, Teachers colleges: The weakest link, viewed 11 January 2020, from http://ncee.org/2018/11/teachers-colleges-the-weakest-link/.

Van den Heuvel-Panhuizen, M. (ed.), 2008, Children learn mathematics: A learningteaching trajectory with intermediate attainment targets for calculation with whole numbers in primary school, Sense Publishers, Rotterdam.

Van der Berg, S. \& Gustafsson, M., 2019, 'Educational outcomes in post-apartheid South Africa: Signs of progress despite great inequality', in N. Spaull \& J. Jansen (eds.), South African schooling: The enigma of inequality, pp. 25-46, Springer, Cham, Switzerland.

Van der Berg, S. Gustafsson, M. \& Malindi, K., 2020, Education and skills for the economy and links to labour markets in South Africa. Report for the Economic Task Team of the National Planning Commission, Stellenbosch University: Research on Socio-Economic Policy, Stellenbosch.

Venkat, H., 2019, 'Improving early number learning in contexts of disadvantage. Invited plenary lecture', in J. Novotná \& H. Moraová (eds.), Proceedings of the International Symposium for Elementary Mathematics Teaching (SEMT), Aug 18-22, Charles University, pp. 40-52.

Venkat, H., 2020, ‘5 year review report, phase 2-2016-2020: Scaling up interventions showing promise', Unpublished Report on Wits Maths Connect - Primary.

Venkat, H. \& Askew, M., 2018, 'Mediating primary mathematics: Theory, concepts and a framework for studying practice', Educational Studies in Mathematics 97(1) 71-92. https://doi.org/10.1007/s10649-017-9776-1

Venkat, H., Bowie, L. \& Alex, J.K., 2017, 'The design of a common diagnostic mathematics assessments for first year B.Ed. students', Unpublished presentation at the South African Education Research Association (SAERA) Conference, October 22-26, Port Elizabeth.

Venkat, H. \& Spaull, N., 2015, 'What do we know about primary teachers' mathematical content knowledge in South Africa? An analysis of SACMEQ 2007 International Journal of Educational Development 41, 121-130. https://doi. org/10.1016/j.ijedudev.2015.02.002

Wright, R.J., Martland, J. \& Stafford, A.K., 2006, Early numeracy: Assessment for teaching and intervention, Sage Publications, London. 